hospital with complications following a bout of flu have a four to eight week history of symptoms. No studies have compared the response to treatment in vaccinated versus non-vaccinated subjects, but one study of vaccinated, elderly residential patients treated with seasonal prophylaxis reported a 92\% relative reduction. ${ }^{2}$ This emphasises the often forgotten fact that the vaccine is only $70 \%$ effective and has only short term benefits. Rather than neuraminidase inhibitors being an alternative to vaccination, they might be an additional treatment in high risk groups, particularly during epidemics or local outbreaks.

It is difficult to see what important new information about the treatment of flu this meta-analysis offers. As is often the situation with new drugs, information from new studies is essential before neuraminidase inhibitors will become widely used: characterisation of the type and severity of symptoms and end points such as "return to normal activities" should be automatically included; trials should continue for longer; and data collection should provide more details of the type and severity of complications and admissions to hospital. Studies concentrating on the different high risk groups may define those who will gain most benefit from treatment and should incorporate information on vaccination status. In addition to comparative studies of the two neuraminidase inhibitors, combination therapy (vaccination, the M2 inhibitors (amantadine and rimantadine), and neuraminidase inhibitors) may prove an effective means of reducing morbidity and mortality in both treatment and prevention of flu. Results of studies to date do not provide adequate evidence of a cost effective treatment for flu, ${ }^{3}$ but new, more clearly directed research will hopefully clarify which groups will benefit from treatment with neuraminidase inhibitors, alone or in combination with other established treatments.

\section{Competing interests: None declared.}

Advisory Committee on Immunisation Practices. Prevention and control of influenza: recommendations of the Advisory Committee on Immunisation Practices (ACIP). MMWR 2002;51(No RR 3).

2 Peters PH, Gravenstein S, Norwood P, DeBock V, Van Couter A, Gibbens $\mathrm{M}$, et al. Long term use of oseltamivir for the prophylaxis of influenza in a vaccinated frail population. J Am Geriatric Soc 2001;49:1025-31.

Appraisal Committee of the National Institute for Clinical Excellence. Full guidance on the use of zanamivir, oseltamivir and amantidine for the treatment of influenza. Report for the National Institute for Clinical Excellence. February 2003. www.nice.org.uk/

\title{
Social factors and increase in mortality in Russia in the 1990s: prospective cohort study
}

\section{S L Plavinski, S I Plavinskaya, A N Klimov}

College of Public Health, Medical Academy for Postgraduate Studies, Saint Petersburg, Russia S L Plavinski dean

Department of Biochemistry, Institute for Experimental Medicine, Saint Petersburg, Russia S I Plavinskaya leading researcher A N Klimov principal researcher

Correspondence to: S L Plavinski splavinskij@mail.ru

BMJ 2003;326:1240-2

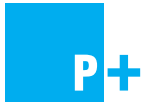

A figure showing details of

recruitment and

follow up and a table showing alcohol intake can be found on bmi.com

\section{Abstract}

Objective To determine the association between social factors and the increase in mortality in Russia in the 1990s.

Design Prospective population cohort study. Setting Saint Petersburg, Russia.

Participants Two cohorts of men aged 40-59 years randomly selected from district voting list: 3907 screened in 1975-7 and 1467 in 1986-8.

Main outcome measures Education, various health related measures, alcohol intake. Mortality in subsequent 10 years.

Results There was no recorded increase in mortality in men with university degrees. The relative risk in the second cohort compared with the first was $0.92(95 \%$ confidence interval 0.67 to 1.24 ). For participants with only high school education it was significantly higher in the second cohort $(1.32,1.02$ to 1.71$)$. The most pronounced differences were found among participants with the lowest level of education, in which the relative risk was 1.75 (1.44 to 2.12$)$. The same pattern held for coronary vascular disease and cancer mortality.

Conclusion In Russia men in the lower socioeconomic groups were most affected by the sharp increases in mortality in the 1990s.

\section{Introduction}

The rapid increase in mortality in Russia in the 1990s was a development previously not reported in any eco- nomically developed country. For men life expectancy decreased from about 64 years in 1990 to 59 years in 1993. ${ }^{1}$ There is still controversy as to who suffered most from concurrent economic breakdown. Several large prospective studies on mortality from ischaemic heart disease in Russia offer a unique opportunity to identify subpopulations that were more affected.

\section{Methods}

The study sample comprised two cohorts of men living in the Petrogradsky district of Leningrad (now Saint Petersburg). The first cohort was 5000 randomly selected men from the 1974 voting list who were born from 1916 to 1935 . The response rate was $78 \%$ (3907 men were screened). The second cohort was selected from the 1985 voting list (men born from 1927 to 1946). In total 1000 men aged 40-49 and 1000 aged 50-59 were randomly selected for screening. The response rate was $71 \%$ for $40-49$ year olds and $76 \%$ for 50-59 year olds (total 1467 men screened). The screening procedure has been described in detail elsewhere ${ }^{2-4}$ and was the same for the two groups.

The follow up study began in January 1979. If the state registration organ (ZAGS) indicated that participants were no longer registered at the designated addresses we tried to contact them if they had moved away or contacted their relatives or neighbours if they had died. Overall loss to follow up was 3\%. In the second cohort we were unable to get data for 15 men who had died. 

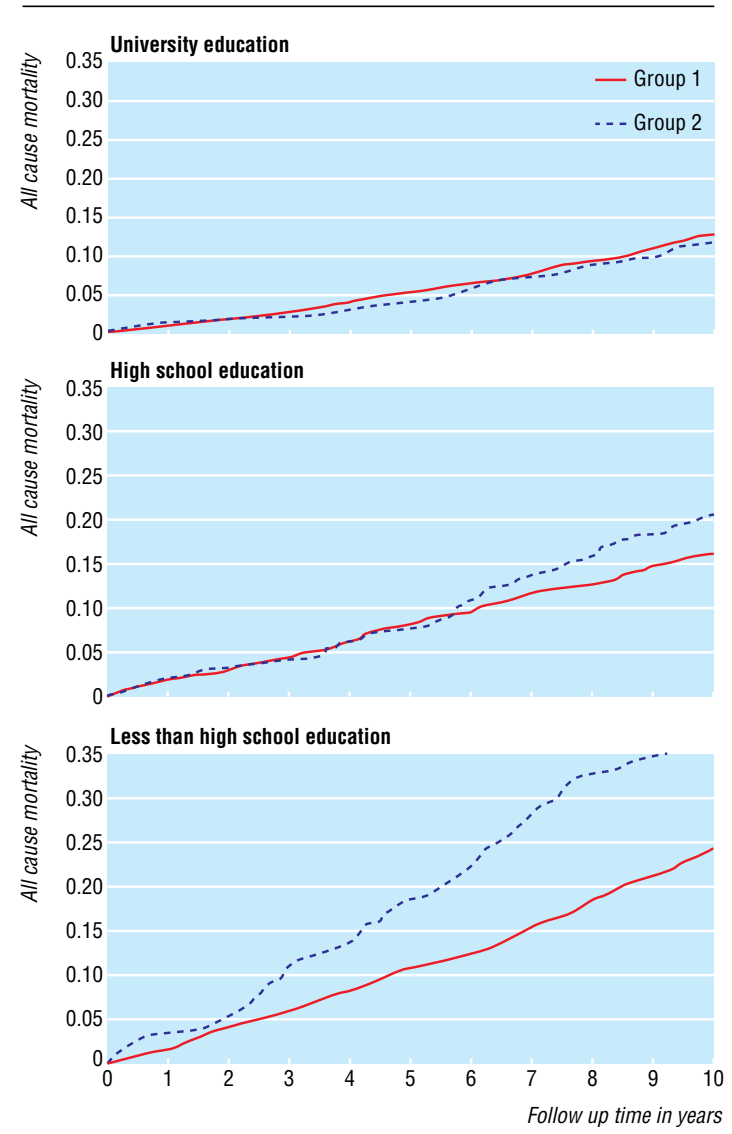

All cause mortality among two cohorts according to level of education (group 1 screened in 1975-7, group 2 screened in 1986-8)

The first cohort was followed up for a mean of 18.1 years, and there were 1890 deaths. The second cohort was followed up for a mean of 11.2 years, and there were 323 deaths. The first day of follow up was the day the last participant from this cohort was screened: 6 July 1977 for the first cohort and 21 August 1988 for
Table 1 General characteristic of two screened groups of men. Figures are means (SD) unless stated otherwise

\begin{tabular}{lcc} 
Indicator & $\mathbf{1 9 7 5 - 7}(\mathbf{n = 3 9 0 7 )}$ & $\mathbf{1 9 8 6 - 8}(\mathbf{n}=\mathbf{1 4 6 7})$ \\
\hline Age (years) & $48.5(5.6)$ & $49.6(5.2)$ \\
\hline Total cholesterol $(\mathrm{mmol} / \mathrm{l})$ & $5.67(1.03)$ & $5.81(11.07)$ \\
\hline High density lipoprotein cholesterol $(\mathrm{mmol} / \mathrm{l})$ & $1.42(0.46)$ & $1.37(0.40)$ \\
\hline Trigylcerides $(\mathrm{mmol} / \mathrm{l})$ & $1.36(1.31)$ & $1.37(0.78)$ \\
\hline Systolic blood pressure $(\mathrm{mm} \mathrm{Hg})$ & $139.2(22.8)$ & $133.5(23.4)$ \\
\hline Diastolic blood pressure $(\mathrm{mm} \mathrm{Hg})$ & $89.3(12.1)$ & $87.2(12.9)$ \\
\hline Body mass index $\left(\mathrm{kg} / \mathrm{m}^{2}\right)$ & $26.0(3.5)$ & $25.8(3.8)$ \\
\hline Current smokers $(\%)$ & 58.3 & 76.3 \\
\hline Smoked in past $(\%)$ & 80.9 & 27 \\
\hline Education $(\%):$ & & 33 \\
\hline Less than high school & 42 & 40
\end{tabular}

the second cohort (see webextra figure). We have presented data for the first 10 years of follow up.

We used Kaplan-Meier survival curves and calculated relative risks and confidence intervals from person time data. We used the exact Poisson method to calculate confidence intervals. ${ }^{5}$ Statistical analysis was performed with SAS system, version 6.12 for Windows (SAS Institutes, Cary, NC).

\section{Results}

The two groups screened closely resembled each other in terms of age, place of residence, structure, behavioural risk factors, and biological indicators (table 1). The number of people with education less than high school decreased because the second cohort included only those born after the Bolshevik revolution, when high school education became mandatory.

Table 2 and the figure show our main results. Among participants with university education all cause mortality in both cohorts was almost the same: 12.8 per 1000 person years of observation for the first cohort and 11.7 for the second (relative risk 0.92, 95\%

Table 2 Mortality in two cohorts according to cause of death during 10 years of follow up

\begin{tabular}{|c|c|c|c|c|c|}
\hline & \multicolumn{2}{|l|}{ First cohort } & \multicolumn{2}{|c|}{ Second cohort } & \multirow[b]{2}{*}{ Relative risk $(95 \% \mathrm{Cl})$} \\
\hline & No of deaths/person years* & Mortality & No of deaths/person years* & Mortality & \\
\hline \multicolumn{6}{|l|}{ Total mortality } \\
\hline University degree & $147 / 11487$ & 12.8 & $63 / 5379$ & 11.7 & $0.92(0.67$ to 1.24$)$ \\
\hline High school & $159 / 9464$ & 16.8 & $98 / 4419$ & 22.2 & $1.32(1.02$ to 1.71$)$ \\
\hline Less than high school & $404 / 14537$ & 27.8 & $150 / 3084$ & 48.6 & 1.75 (1.44 to 2.12$)$ \\
\hline \multicolumn{6}{|l|}{ Cardiovascular disease } \\
\hline University degree & $86 / 11487$ & 11.2 & $26 / 5379$ & 6.7 & 0.64 (0.40 to 1.01$)$ \\
\hline High school & $74 / 9464$ & 11.1 & $50 / 4419$ & 14.3 & 1.45 (0.99 to 2.10$)$ \\
\hline Less than high school & $173 / 14537$ & 17.4 & $73 / 3084$ & 26.6 & 1.99 (1.49 to 2.63$)$ \\
\hline \multicolumn{6}{|l|}{ Coronary heart disease } \\
\hline University degree & $64 / 11487$ & 9.8 & $17 / 5379$ & 8.6 & 0.57 (0.31 to 0.98$)$ \\
\hline High school & $54 / 9464$ & 5.7 & $36 / 4419$ & 8.1 & 1.43 (0.91 to 2.22$)$ \\
\hline Less than high school & $113 / 14537$ & 4.4 & $46 / 3084$ & 5.5 & 1.92 (1.33 to 2.73$)$ \\
\hline \multicolumn{6}{|l|}{ Cancer } \\
\hline University degree & $35 / 11487$ & 9.2 & $18 / 5379$ & 7.4 & 1.10 (0.59 to 1.99$)$ \\
\hline High school & $46 / 9464$ & 4.9 & $23 / 4419$ & 5.2 & $1.07(0.62$ to 1.80$)$ \\
\hline Less than high school & $106 / 14537$ & 2.4 & $40 / 3084$ & 5.8 & 1.78 (1.20 to 2.58$)$ \\
\hline \multicolumn{6}{|c|}{ Violent/accidental deaths } \\
\hline University degree & $13 / 11487$ & 1.1 & $2 / 5379$ & 0.4 & 0.33 (0.04 to 1.45$)$ \\
\hline High school & $15 / 9464$ & 1.6 & $9 / 4419$ & 2.0 & 1.29 (0.50 to 3.13$)$ \\
\hline Less than high school & $50 / 14537$ & 3.4 & $11 / 3084$ & 3.6 & 1.04 (0.49 to 2.02$)$ \\
\hline
\end{tabular}




\section{What is already known on this topic}

In the mid-1990s the former Soviet Union experienced unprecedented increases in mortality especially among men of working age and in the urban population

Increase in mortality associated with lower educational attainment has been noted in Russia

\section{What this study adds}

The increase in mortality in Russia did not affect all social groups equally

The greatest increases were among those with the least education

Alcohol consumption may account for some but not all of this increase

confidence interval 0.67 to 1.24$)$. Mortality among men with only high school education was the same in both cohorts for the first six years of follow up (figure), but then diverged and at the end of follow up was significantly higher in the second cohort (1.32, 1.02 to 1.71). The largest differences were in men with the least education (less than high school). All cause mortality was higher almost from the beginning of the follow up, steadily rising with time and reaching 48.6 per 1000 person years for the second cohort at the end of follow up. Ten years before it was $43 \%$ lower (27.8 per 1000 person years; $1.75,1.44$ to 2.12 ). The increase in mortality has been noted for cardiovascular disease and cancer, though it was not significant for coronary heart disease. Increases in mortality from cardiovascular disease and cancer were highest among men with the least education (1.99, 1.49 to 2.63 ; and $1.78,1.20$ to 2.58 , respectively). Surprisingly, there was no significant increase in the rate of accidental/violent deaths.

We divided participants into two groups: those who drank more than $150 \mathrm{~g}$ of alcohol during the week before screening and those who drank less. In both groups mortality increased in the 1990s (see webextra table A). This increase was more pronounced than the increase in mortality associated with increased alcohol consumption within each cohort. Among men with the least education, mortality in the 1990 s increased $60-80 \%$ compared with $8-22 \%$ increase associated with increased alcohol consumption (the relative risk for alcohol related mortality was $1.27,1.02$ to 1.57 , in the first cohort and 1.08, 0.73 to 1.57 , in the second cohort).

\section{Discussion}

In 1980 the Black report first presented evidence to show the links between the socioeconomic environment and health and wellbeing. ${ }^{6}$ In the United Kingdom between 1976-81 and 1986-92 the mortality gap between socioeconomic classes I and II and classes IV and V increased. ${ }^{7}$ The higher mortality among people with little education has also been well documented in Russian epidemiological studies. ${ }^{3} 8$

Our data show that the increase in mortality in the mid-1990s disproportionately affected men with low education, with an increase of almost $75 \%$ from the level of the mid-1980s. The reason why social changes have struck mostly the least educated could be that for those sectors of society, breakdown of the socialist state could engender a sense of catastrophe. ${ }^{9}$ The mediator between stress and mortality could be alcohol. Russian men commonly use alcohol because it "helps them to forget everyday cares and difficulties." ${ }^{\prime 10}$ Also alcohol related problems were more common among the less educated respondents. However, our analysis shows that the increase in mortality in Russia was socially determined, and though alcohol may play a part in this process it is not the sole factor.

We thank all those who participated in data collection and follow up of participants: G Ilyina, A Katrushenko, V Khoptiar, I Klenina, V Konstantinov, B Lipovetsky, E Magracheva, T Maslova, G Mirer, N Muchina, N Nikulcheva, N Parfenova, D Shestov, Y Slepenkov, V Tryufanov, L Vassilieva, N Zhukovskaya. Contributors: SLP proposed the initial hypotheses, analysed the data. and wrote the paper. SIP participated in data collection and analysis, provided expert knowledge of the mortality classification and determinants of mortality, and provided ideas for study execution and analysis. ANK conceived the study, supervised and directed data collection, and is guarantor. All authors commented on the paper. ANK was the principal investigator in the larger project of which this study is part.

Funding: Cohort study was funded partially by $\mathrm{NIH}$ grants NO-1HR12243-L/HR/NHLBI, NO-1HV08112/HV/NHLBI and by the Soviet (then Russian) Academy of Medical Sciences. The guarantor accepts full responsibility for the conduct of the study, had access to the data, and controlled the decision to publish.

Competing interests: None declared.

Ethical approval: The USSR Lipid Research Clinics cohort study has been carried out under a government-to-government agreement between the United States and the Union of Sovie Socialist Republics on a joint programme in cardiovascular diseases, signed in 1972 .

1 Shkolnikov V. The Russian health crisis of the 1990s in mortality dimensions. Cambridge, MA: Harvard Center for Population and Development Studies, 1997 (Working Paper Series No 97.01)

2 Lipid Research Clinics Population Studies Data Book. Vol III. The USSR first prevalence study. Bethesda: National Institutes of Health, 1986 (NIH Publication No 87-2727).

3 Klimov AN, ed. Epidemiology and risk factors of ischemic heart disease [In Russian]. Leningrad: Medicine, 1989.

Plavinskava SI. The role of risk factors in the prognosis of CHD in the male or female population of a big industrial city [dissertation in Russian]. Saint female population of a big industrial city [dissertation in

5 Sahai H, Khurshid A. Statistics in epidemiology. Boca Raton: CRC Press, 1996.

6 Black D, Morris J, Smith C, Townsend P. Inequalities in health: report of a working group. London: DHSS, 1980

Acheson D. Independent inquiry into inequalities in health, report of the scientific advisory group. London: Stationery Office, 1998.

8 Dennis B, Zhukovsky G, Shestov D, Davis C, Deev A, Kim H, et al. The association of education with coronary heart disease mortality in the USSR Lipid Research Clinics Study. Int J Epidemiol 1993;22:420-7.

9 Simpura J, Eremitcheva G, Evdokimova E, Mannila S, Nosova T, Pakkasvirta T, et al. No limits to patience? Experience of the Russian economic crisis of 1998 in the everyday lives of the middle-class families in St. crisis of 1998 in the everyday lives of

10 Palosuo H. Uutel A Zhuravleva I, Lakomova N. Observations on the use Palosuo H, Uutel A, Zhuravleva I, Lakomova N. Observations on the use
of alcohol in Helsinki and Moscow in 1991. In: Simpura J, Levin B, eds. Demystifying Russian drinking. Saarijarvi: STAKES, 1997:149-74. (Accepted 7 April 2003)

\section{Endpiece}

\section{The three stages of a man's life}

He believes in Santa Claus

He doesn't believe in Santa Claus

He IS Santa Claus

Author unknown

Fred Charatan, retired geriatric physician, Florida 